ORIENTAL JOURNAL OF CHEMISTRY

An International Open Free Access, Peer Reviewed Research Journal

www.orientjchem.org
ISSN: 0970-020 X

CODEN: OJCHEG

2015, Vol. 31, No. (1):

Pg. 353-356

\title{
Steroid from the Seeds of Artabotrys odoratissimus
}

\author{
SUBEDAR PRASAD ${ }^{1}$ and CHITRASEN GUPTA ${ }^{2 *}$ \\ 'Department of Chemistry, M.M. T.D. College, Ballia, India. \\ ${ }^{2}$ Department of Chemistry, Kutir Post Graduate College, Chakkey, Jaunpur, India. \\ ${ }^{*}$ Corresponding author E-mail: chitrasengupta@yahoo.co.in \\ http://dx.doi.org/10.13005/ojc/310141
}

(Received: December 16, 2014; Accepted: January 20, 2015)

\begin{abstract}
A steroid has been isolated from the seeds of Artabotrys odoratissimus (Annonaceae) and its structure has been established as (3ß,22E)-ergosta-5,7,22-trien-3-ol by spectroscopic and chemical studies. By chemical correlations, it has been identified as a known compound ergosterol. This is the first report of isolation of ergosterol from this plant.
\end{abstract}

Key words: Artabotrys odoratissimus, Annonaceae, Ergosterol.

\section{INTRODUCTION}

Artabotrys odoratissimus, Wight \& Arn. [(Syn: A. uncinatus (Lam.) Merr. and Annona hexapetalus (L. f.) Bhandari)] of the family Annonaceae is a shrub distributed in tropical and temperate Asia from the southern part of China to India. The plant, known for its essential oils, is used for the treatment of malaria and scrofula in traditional Chinese medicine ${ }^{1}$. Isolation of aliphatic alcohols and esters $^{2}$, sesquiterpenes ${ }^{3}$, alkaloids ${ }^{4}$, anthraquinones ${ }^{5}$ and four new triterpenes ${ }^{6}$ were earlier reported from the plant. In previous works, isolation of flavonol glycosides ${ }^{7}$ is also reported from the leaves of the plant. In this paper we report the isolation of an ergosteroid from the n-hexane extract of defatted seeds of Artabotrys odoratissimus.

\section{MATERIALAND METHODS}

\section{Isolation procedure}

$500 \mathrm{~g}$ seeds of $A$. odoratissimus were collected from the campus of Banaras Hindu University, Varanasi, India, milled and left overnight in $n$-hexane to defat. Then filtered and residue was extracted with $\mathrm{n}$-hexane in a soxhlet extractor for 16 hours. Systematic column chromatographic fractionation of the $n$-hexane extract by with mixture of solvents i.e., n-hexane and benzene (8:2) resulted in isolation of an ergosteroid, named ergosterol.

\section{Chemical and physical analysis}

Melting point was taken on a Yazawa hot

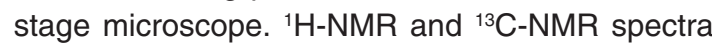
were recorded on $300 \mathrm{MHz}$ or $500 \mathrm{MHz} / 125 \mathrm{MHz}$ on Bruker 300 or JEOL GSX-500 MHz spectrometer 
using tetramethyl silane (TMS) as a internal reference. The chemical shift value are reported in delta (d, ppm) units. Silica gel for column chromatography refers to E. Merck (India) Ltd. (60120 mesh). Thin layer chromatography plates were prepared with silica gel-G of E. Merck (India) Ltd. and spot were visualized in iodine vapour or by $5 \%$ $\mathrm{H}_{2} \mathrm{SO}_{4}$ in ethanol and heating the plates at $110^{\circ} \mathrm{C}$ for 10 minutes. Compound was routinely dried over $\mathrm{P}_{2} \mathrm{O}_{5}$ for 24 hours in vacuum and was tested for purity by thin layer chromatography. Anhydrous sodium sulphate was routinely used for drying the organic solvents.

\section{RESULTS AND DISCUSSION}

The single spot nature of compound was determined by exposure of the TLC plates to iodine vapours as well as charring the plates after spraying with $5 \%$ ethanolic sulphuric acid at $110^{\circ} \mathrm{C}$ for 10 minutes. The compound responded positive to Liebermann-Burchard test, when its solution in chloroform and acetic anhydride was treated gently with concentrated sulphuric acid; it developed pink colouration at the junction of two layers which turned to be gray on prolonged keeping, which shows steroidal nature of the compound. The $R_{f}$ values of compound in different solvent systems are tabulated in table-1.
Further elution of same column yielded $1.73 \mathrm{~g}$ of compound as white crystalline solid and recrystalised from methanol, m.p.: $165-168^{\circ} \mathrm{C},[\mathrm{a}]_{\mathrm{D}}$ $135^{\circ}$ (c, $0.1, \mathrm{CHCl}_{3}$ ). EIMS : $\underline{\mathrm{m}} / \underline{\underline{z}}$ (rel. int.) 396 (100) $\left(\mathrm{M}^{+}\right), 386$ (15), 363 (71), 353 (7), 337 (29), 316 (4), 301 (5), 283 (9), 271 (25, 256 (50), 253 (22), 213 (213), 199 (14), 171 (16), 157 (20), 137 (29), 129 (29), 109 (29), 95 (46), 81 (65), 55 (61), 41 (61).

IR spectrum of compound showed broad absorption at $\lambda_{\max } 3400 \mathrm{~cm}^{-1}$ for hydroxyl group. It was, therefore, inferred from IR spectrum of compound that it bears hydroxyl group in the molecule. The ${ }^{1} \mathrm{H}$-NMR spectrum of compound was measured in $\mathrm{CDCl}_{3}$ solution at $500 \mathrm{MHz}$. The spectrum showed (Table 2) signals for a number of methyl groups in upfield region, a carbinyl hydrogen signal at $\mathrm{d} 3.642,1 \mathrm{H}$, heptet, signals for four olefinic hydrogens from d 5.199 to 5.60 ppm and a large number of signals ranging from d 1.2 to $2.5 \mathrm{ppm}$ for methine and methylinic hydrogens.

A careful analysis of the signals in upfield region from $\mathrm{d} 0.62$ to $1.05 \mathrm{ppm}$ revealed that a compound possess two tertiary methyl groups at d 0.631 and $0.947,3 \mathrm{H}$ singlet, each which is probably due to 18 and 19-methyl groups of a steroid molecule. The four methyl doublets at $\mathrm{d} 0.824(\mathrm{~J}=$ $6.6 \mathrm{~Hz}) ; 0.834(\mathrm{~J}=6.6 \mathrm{~Hz}) 0.918(\mathrm{~J}=6.6 \mathrm{~Hz})$ and

Table 1: $\mathbf{R}_{\mathrm{f}}$ value of compound in different solvent system

\begin{tabular}{lcc}
\hline Solvent system & Ratio & $\mathbf{R}_{\mathrm{f}}$ value \\
\hline Benzene & - & 0.14 \\
Benzene : Chloroform & $8.5: 1.5$ & 0.42 \\
Benzene : Ethyl acetate & $9: 1$ & 0.56 \\
Benzene : Methanol & $5: 5$ & 0.60 \\
\hline
\end{tabular}

Table 2: ${ }^{1} \mathrm{H}-\mathrm{NMR}$ in $\mathrm{CDCl}_{3}$ at $500 \mathrm{MHz}$ compound (Ergosterol)

\begin{tabular}{lccc}
\hline S. N. & No. of Carbons & Chemical Shift & Coupling constant J (Hz) \\
\hline 1. & $3 \mathrm{H}$ & $0.631 \mathrm{~s}$ & - \\
2. & $3 \mathrm{H}$ & $0.824 \mathrm{~d}$ & 6.6 \\
3. & $3 \mathrm{H}$ & $0.834 \mathrm{~d}$ & 6.6 \\
4. & $3 \mathrm{H}$ & $0.918 \mathrm{~d}$ & 6.6 \\
5. & $3 \mathrm{H}$ & $0.947 \mathrm{~s}$ & 7.2 \\
6. & $3 \mathrm{H}$ & $1.037 \mathrm{~d}$ & \\
7. & $1 \mathrm{H}$ & 3.642 heptet & \\
\hline
\end{tabular}




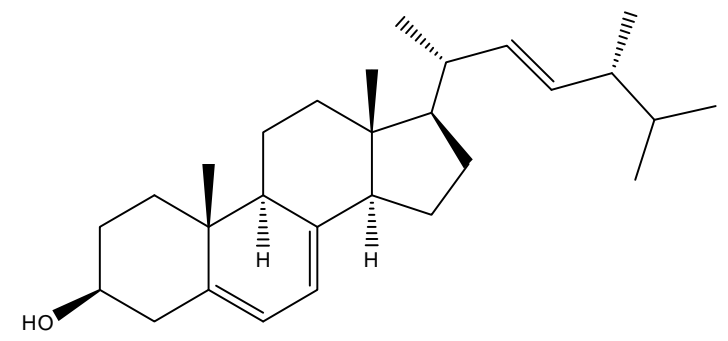

Fig. 1: Ergosterol

$1.037(\mathrm{~J}=7.2 \mathrm{~Hz})$ suggests that these are due to secondary methyl groups present in the side chain of an ergostane. Amongst these four secondary methyl groups one at d 1.037 was attributed to be due to C-21 methyl group and two secondary methyl groups at d $0.824(6.6 \mathrm{~Hz})$ and d $0.834(6.6 \mathrm{~Hz})$ were due to terminal isopropyl group of the side chain present in normal ergostane type of steroid.

The carbinyl hydrogen signal at d 3.642 heptet was obviously considered for the hydrogen bound to C-3-position and is \pm to $\mathrm{C}_{3}$-b-hydroxyl group. It is a general characteristic of $\mathrm{C}-3-\mathrm{a}-\mathrm{H}$, which appears as heptet in nearly all C-3-hydroxylated steroids. The presence of C-3-hydroxyl is further supported by acetylation of compound with acetic anhydride and pyridine at room temperature which yielded monoacetate of compound, analyzed for $\mathrm{C}_{30} \mathrm{H}_{46} \mathrm{O}_{2}$. The IR spectrum, of acetylated compound showed the presence of ester carboxyl absorption at $1736 \mathrm{~cm}^{-1}$ with simultaneous disappearance of band for hydroxyl absorption around $3400 \mathrm{~cm}^{-1}$. This showed that only oxygen present in compound is acylable secondary hydroxyl group.

The presence of four olefinic protons in the molecule of compound is evidence by the<smiles>CC(=O)O[C@H]1CC[C@@]2(C)C(=CC=C3[C@@]2(C)CC[C@]2(C)[C@@H]([C@@H](C)/C=C/[C@H](C)C(C)C)CC[C@]32C)C1</smiles>

Fig. 2: Ergosterol-3-acetate

signals at d 5.199, 2H, multiplet, d 5.395, and d $5.569,1 \mathrm{H}$ each. The one at $\mathrm{d} 5.199,2 \mathrm{H}$ multiplet was consider to be for the hydrogens associated with the double bond present in the side chain of the molecule whereas the two signals at 5.395 and $d 5.569$ were attributed to two conjugated double bonds which can only be possible in the $B$ ring of a steroid nucleus and on the basis of the data presented so for the structure of compound can be written as:

A search of literature has revealed that this is a known ergosteroid and has earlier reported from: Engleromyces goetzei ${ }^{8}$, Polyporous umbellatus $^{9}$, Phycomyces blakesleeanus ${ }^{10}$ and Agelas sceptrum ${ }^{11}$.

This is the first report of isolation of ergosterol from the seeds of Artabotrys odoratissimus.

\section{ACKNOWLEDGEMENTS}

The authors thank Prof. Yoshinori Fujimoto, Department of Chemistry and Materials Science, Tokyo Institute of Technology, Meguro, Tokyo 1528551, Japan for providing spectral analysis and structural information.

\section{REFERENCES}

1. Green et al, J. Cancer Chemether, 1972, 3.

2. Rupprecht et al, Heterocycles, 1986, 24 (3), 1179.

3. Mc Cloud, T.G.; Experientia, 1987, 43.

4. The Wealth of India: raw materials, A Dictionary of India raw Material and Industrial Products, Council of Scientific
Industrial Research, New Delhi, Vol. I. PP. 119 (1952).

5. A Dictionary of the Economic Products of India vol.1 p 322.

6. Gupta, C.; Prasad, S.; Sahai, M.; Asai, A; Hara, N; Fujimoto, Y., Helvetica Chimica Acta , 2010 93 (10) 1925. 
7. Singh, A.P.; Sahai, M., Planta Medica, 1996, 62 (2), 192.

8. Zhan, Z.; Sun, H.; Wu, H.; Yue, J., Acta Botanica Sinica, 2003, 45 (2), 248.

9. Lu, W.; Adachi; Kano, K.; Yasuta, A.; Toriizuka, K.; Ueno, M.; Horikoshi, I., Chem. Pharm.
Bull., 1985, 33 (11), 5083.

10. Mercer, E.I.; Bartlett, K., Phytochemistry, 1974, 13 (7), 1099.

11. Hu, J.- F.; Kelly, M.; Hamann, M.T., Steroids, 200267 (9), 743. 